\title{
Endogenous opiate analgesia induced by tonic immobility in guinea pigs
}

C.R.A. Leite-Panissi, C.L. Rodrigues,

M.R. Brentegani and L. Menescal-de-Oliveira

\author{
Departamento de Fisiologia, Faculdade de Medicina de Ribeirão Preto, \\ Universidade de São Paulo, Ribeirão Preto, SP, Brasil
}

\section{Correspondence \\ L. Menescal-de-O liveira \\ Departamento de Fisiologia \\ FMRP, USP \\ Av. Bandeirantes, 3900 \\ 14049-900 Ribeirão Preto, SP \\ Brasil \\ Fax: + 55-16-633-0017 \\ E-mail: Imdolive@fmrp.usp.br}

Presented at the XV Annual Meeting of the Federação de Sociedades de Biologia Experimental, Caxambu, MG, Brazil, August 23-26, 2000.

Research supported by CNPq, CAPES and FAPESP (No. 97/14286-9).

Received April 10, 2000

Accepted November 29, 2000

\section{Abstract}

A function of the endogenous analgesic system is to prevent recuperative behaviors generated by tissue damage, thus preventing the emission of species-specific defensive behaviors. Activation of intrinsic nociception is fundamental for the maintenance of the behavioral strategy adopted. Tonic immobility (TI) is an inborn defensive behavior characterized by a temporary state of profound and reversible motor inhibition elicited by some forms of physical restraint. We studied the effect of TI behavior on nociception produced by the formalin and hot-plate tests in guinea pigs. The induction of TI produced a significant decrease in the number of flinches $(18 \pm 6$ and $2 \pm 1$ in phases 1 and 2$)$ and lickings ( $6 \pm 2$ and $1 \pm 1$ in phases 1 and $2)$ in the formalin test when compared with control $(75 \pm 13$ and $22 \pm$ 6 flinches in phases 1 and 2;28 \pm 7 and $17 \pm 7$ lickings in phases 1 and 2). In the hot-plate test our results also showed antinociceptive effects of TI, with an increase in the index of analgesia 30 and $45 \mathrm{~min}$ after the induction of TI $(0.67 \pm 0.1$ and $0.53 \pm 0.13$, respectively $)$ when compared with control $(-0.10 \pm 0.08$ at $30 \mathrm{~min}$ and $-0.09 \pm 0.09$ at 45 $\mathrm{min})$. These effects were reversed by pretreatment with naloxone (1 $\mathrm{mg} / \mathrm{kg}, i p$ ), suggesting that the hypoalgesia observed after induction of TI behavior, as evaluated by the algesimetric formalin and hot-plate tests, is due to activation of endogenous analgesic mechanisms involving opioid synapses.

\section{Introduction}

Many antinociceptive systems have been identified which modulate nociception at different levels of the neural axis $(1,2)$. Endogenous analgesic mechanisms are influenced by fear and by a defensive system which functions to inhibit pain when an organism's safety is threatened (3). One of the adaptive functions of endogenous analgesic mechanisms is to prevent the recuperative behaviors

\section{Key words}

- Tonic immobility

- Guinea pig

- Antinociception

- Opioids

- Naloxone

- Analgesia generated by tissue damage from disrupting the species-specific defense reactions that an animal uses in self-defense (4). The behavioral defense strategy adopted by the animal takes into account, in addition to the distance between prey and predator (5), the degree of threat posed by each situation (6). Thus, when danger is distant the animal may freeze in order to go unperceived, or may flee, although the latter strategy may call the attention of the predator. In the case of pro- 
longed physical contact with no possibility of escape for the prey, the animal displays the tonic immobility (TI) behavior. It is the last resource used by the prey to reduce the probability of continued attack on the part of the predator, thus being of adaptive value. This response is characterized by a reversible state of profound physical inactivity and a relative lack of responsiveness to the environment (5).

Within this context, the defensive behavioral responses elicit the activation of an antinociceptive system so that the strategy adopted will be successful. However, it is highly improbable that analgesia associated with active flight and analgesia associated with TI could be mediated in a similar manner in terms of form (active/passive) and function (avoiding capture $v s$ reducing predator interest upon capture) since these defense reactions are obviously very different. During an active defense response such as flight or struggling, the analgesia involved does not seem to be opioid, whereas during $\mathrm{TI}$, a response that may last seconds or hours, analgesia appears to be of the opioid type (7). However, the literature has reported little evidence supporting this hypothesis.

Like TI, freezing is an inhibitory speciesspecific behavior (5). However, whereas TI is a post-encounter response, freezing involves the anticipation of a situation of danger and is therefore a pre-encounter response. In the laboratory, freezing can be triggered by various Pavlovian fear stimuli and can also produce a reduction in pain sensitivity as indicated by a suppression of formalininduced recuperative behavior. This decrease in responsiveness to painful stimulation is reversed by opioid antagonists (8). On the other hand, it has been shown in mice that repeated pinching of the scruff of the neck produces catalepsy and analgesia that are functionally interdependent, and that analgesia is abolished by naloxone (9).

Despite these remarkable advances, little is known about the natural circumstances under which endogenous analgesia systems are activated. On this basis, the objective of the present study was to investigate the possibility that TI behavior activates the endogenous antinociceptive system and also to assess the role of the opioid mechanism in this response. For this purpose, we induced TI behavior in the laboratory and observed its effect on the nociception produced by the formalin and hot-plate tests, as well as the action of previous administration of naloxone (a nonselective opioid antagonist) in different groups of guinea pigs.

\section{Animals and Methods}

Adult male guinea pigs (Cavia porcellus, $\mathrm{N}=48$ ) weighing $450-600 \mathrm{~g}$ were used. The animals were kept under controlled temperature $\left(24 \pm 1{ }^{\circ} \mathrm{C}\right)$ on a $12 / 12$-h light/dark cycle (lights on at 6:00 a.m.) in Plexiglaswall cages ( $56 \times 17 \times 39 \mathrm{~cm}, 5$ animals per cage) with free access to water and food. Conditions of animal housing and all experimental procedures obeyed the ethical guidelines of the International Association for the Study of Pain for investigations of experimental pain in conscious animals (10).

The experiments were carried out on 6 groups of 8 guinea pigs each. Group 1 (control) received a $50-\mu 1 s c$ injection of $5 \%$ formalin in saline under the dorsal surface of its right hindpaw. Immediately after the injection, each animal was returned to the observation chamber and its nociceptive responses were recorded for $60 \mathrm{~min}$. The accumulated response number, i.e., the number of flinches and lickings of the injected paw, was measured for each 5-min block. The number of nociceptive responses during the initial two blocks (10-min period) was regarded as the first-phase response (phase 1). The number of nociceptive responses during and after the fifth block (40-min period) was regarded as the second-phase response (phase 2). In group 2 (TI), one day before the formalin test the animals were individually sub- 
mitted to five control maneuvers of TI induction and the duration of the episodes was recorded. The control duration for each group corresponded to the mean of these five TI episodes. On the next day five TI maneuvers were again performed, formalin was immediately injected into the hindpaw and the number of flinches and lickings was recorded as done for group 1. Group $3(\mathrm{Nal}+\mathrm{TI})$ was submitted to the same experimental procedure as group 2 , but naloxone $(1 \mathrm{mg} / \mathrm{kg}$, ip; Sigma Chemical Co., St. Louis, MO, USA) was administered $10 \mathrm{~min}$ before TI induction. The results of the formalin test are reported as mean number of flinches and lickings of the treated paw per 10-min period in phase 1 and phase 2 .

The animals in groups 4, 5 and 6 were submitted to nociceptive thermal stimulation provided by a standard hot-plate apparatus. The hot plate consisted of a Fanem D 112 water bath and pump that heated and circulated $53 \pm 0.5^{\circ} \mathrm{C}$ water through the channeled interior of an aluminum plate. A 28 $\mathrm{cm}$ high, $26-\mathrm{cm}$ long and $18-\mathrm{cm}$ wide Plexiglas cage fitted with a removable lid restrained the guinea pig on the surface of the plate. The hot-plate test is performed by placing the guinea pig on the heated plate and the time (latency) the animal takes to lick its genitals is recorded. When this test was standardized for guinea pigs in our laboratory, we observed that the behavior first exhibited by the animals was to lick the genital region instead of one of the hindpaws, as is usually the case for rats and mice. Latency is considered to be the time taken by the animal to present this response, and the cut-off time was set at $70 \mathrm{~s}$ to avoid possible tissue injury. The baseline comprised 3 measurements of the latency time in the hot-plate test.

In group 4 (control), after determination of the baseline, latency measurements were made in the hot-plate test at 15 -min intervals for $1 \mathrm{~h}$. In group 5, before the measurement of latency in the hot-plate test, the animals were submitted to five maneuvers of TI induction and then to the hot-plate test as done for group 4. Group $6(\mathrm{Nal}+\mathrm{TI})$ was submitted to the same procedure as described for group 5, except that naloxone $(1 \mathrm{mg} / \mathrm{kg}$, ip) was administered $10 \mathrm{~min}$ before the induction of experimental TI. Control TI and hotplate determinations were made on consecutive days before the experiment.

Each hot-plate latency was normalized using an index of analgesia (IA) according to the following formula: hot-plate test - hotplate control/cut-off time - hot-plate control, where hot-plate control is the average of 3 baselines of hot-plate latencies taken at 5min intervals, and hot-plate test is the mean latency recorded of each group.

In groups 2, 3, 5 and 6 the induction of TI was attempted by holding the animal around the thorax with the hands, quickly inverting it, and pressing it down into a V-shaped plywood trough ( $25 \mathrm{~cm}$ long x $15 \mathrm{~cm}$ high). The pressure applied by the hands of the experimenter was proportional to the resistance offered by the animal to the restraining maneuvers. The manual restraint and postural inversion maneuvers used in the laboratory are an attempt to simulate the predation condition. When the animal stopped moving, the experimenter's hands were slowly withdrawn and a chronometer was started to time the duration (in seconds) of the response, which ended when the animal resumed the upright position. When TI occurs, it persists in the absence of restraint for periods varying from a few seconds to several minutes. In our experiments, the mean duration for the groups was about $420 \mathrm{~s}$.

The data concerning the formalin and hot-plate tests are reported as mean \pm SEM and were analyzed by repeated measures multivariate analysis of variance (MANOVA), using time as within-subject factor and treatment (control, TI or Nal + TI) as between-subject factors, followed by oneway analysis of variance and the Duncan test. 
Figure 1 - Hypoalgesia in the formalin test after induction of tonic immobility (TI). Mean number of flinches (A) and lickings (B) per 10-min period in phase $1(0-10$ min after injection of formalin) and phase 2 (20-60 $\mathrm{min}$ ) of the formalin test for the control induction $(T I, N=8)$ and for the group pretreated with naloxone and submitted to TI induction $(\mathrm{Nal}+\mathrm{Tl}, \mathrm{N}=8)$. The vertical bars indicate the standard error of the mean. $* \mathrm{P}<0.05$ compared to control and to the $\mathrm{Nal}+\mathrm{TI}$ group (Duncan test). group (control, $\mathrm{N}=8$ ), after $\mathrm{TI}$
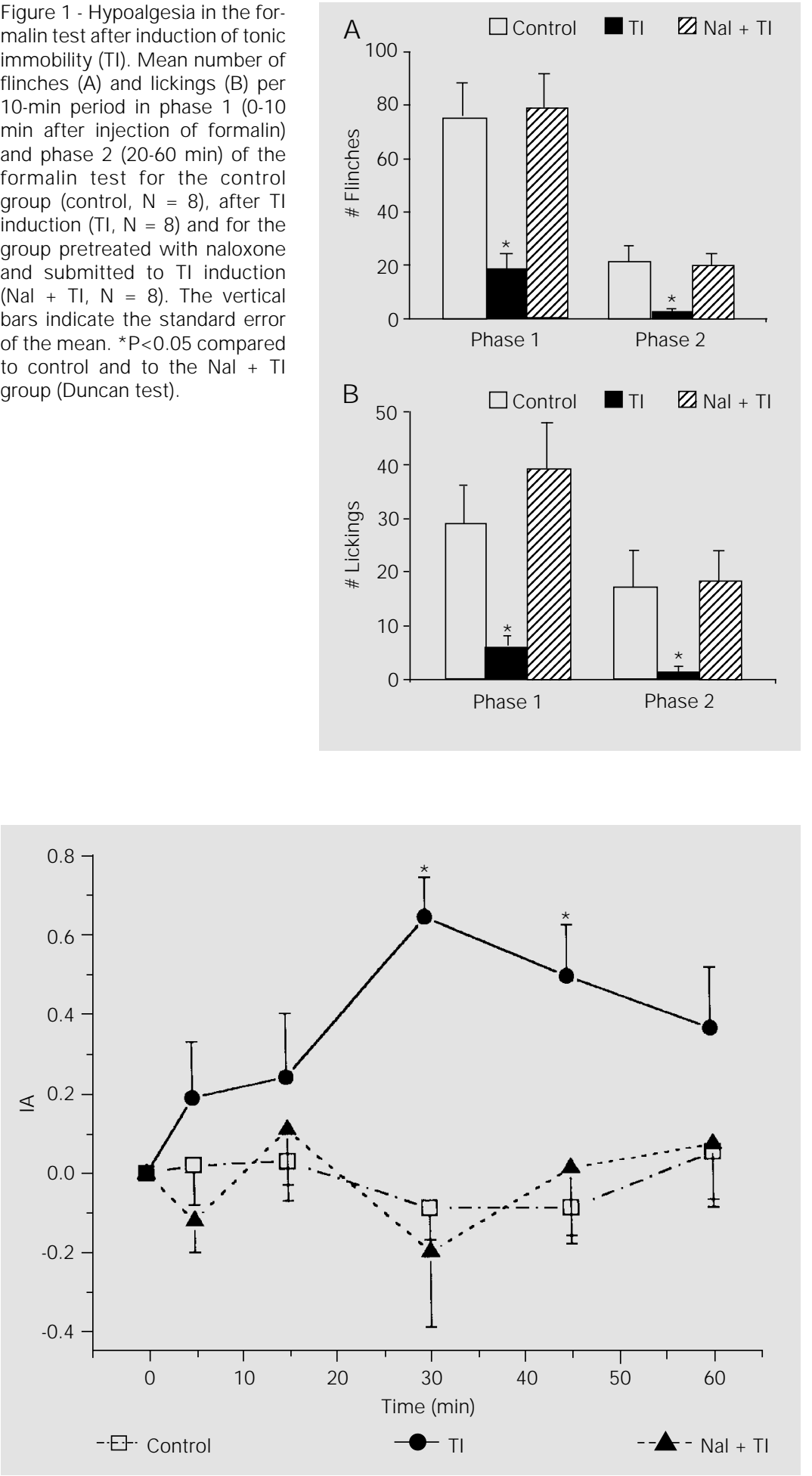

Figure 2 - Index of analgesia (IA) in the hot-plate test for the control group (control, $\mathrm{N}=8$ ), immediately after induction of the five episodes of tonic immobility $(T I, N=8)$, and for the group pretreated with naloxone and submitted to $\mathrm{Tl}$ induction $(\mathrm{Nal}+\mathrm{TI}, \mathrm{N}=8$ ). Time zero represents the baseline and the vertical bars indicate the standard error of the mean. $* \mathrm{P}<0.05$ compared to control and to the $\mathrm{Nal}+\mathrm{Tl}$ group (Duncan test).

\section{Results}

The induction of TI behavior promoted an alteration of nociception in both tests used (formalin and hot plate), with previous naloxone administration inhibiting the antinociception induced by TI. In group 2 the induction of TI produced a decrease in the number of flinches and lickings in phases 1 and 2 (Figure 1) when compared to the control and Nal + TI groups (groups 1 and 3). Analysis of variance applied to the number of flinches and lickings revealed a significant difference between treatments $(\mathrm{F} 2,21=$ $8.46, \mathrm{P}<0.01 ; \mathrm{F} 2,21=4.14, \mathrm{P}<0.05$, to flinches in phases 1 and 2, respectively, and $\mathrm{F} 2,21=6.68, \mathrm{P}<0.01 ; \mathrm{F} 2,21=3.63, \mathrm{P}<0.05$, to lickings in phases 1 and 2, respectively). The Duncan test showed a significant difference between group TI and control $(\mathrm{P}<0.05)$ and between the TI and $\mathrm{Nal}+\mathrm{TI}$ groups $(\mathrm{P}<0.05)$ for both responses (flinches and lickings). In group 5, the TI behavior promoted an increase in the hot-plate latency at the 30- and 45-min intervals (Figure 2) when compared to control and to the Nal + TI group (groups 4 and 6). Analysis of variance applied to hot-plate latency revealed a significant difference between treatments ( $F 2,20$ $=9.78, \mathrm{P}<0.01 ; \mathrm{F} 2,20=5.32, \mathrm{P}<0.01$, at 30 and $45 \mathrm{~min}$, respectively). The Duncan test showed a significant difference between group TI (group 5) and control and the $\mathrm{Nal}+$ TI group (groups 4 and $6, \mathrm{P}<0.05$ ).

Naloxone caused no changes in TI duration episodes in any of the groups studied, suggesting that the function of opioid receptors is not essential for the induction and maintenance of TI behavior.

\section{Discussion}

Some investigators demonstrated that preadministration of naloxone (4) and naltrexone (8) blocks the analgesic response but not the defensive response of freezing. This does not demonstrate that freezing and 
analgesia are mediated by different processes but rather that an opioid synapse is present in the final pathway critical for the expression of analgesia but not in the final pathway producing freezing (11). Similarly, our findings showed that blockade of opioid receptors by naloxone does not alter the duration of TI behavior but can change the antinociception induced by TI as determined in the formalin and hot-plate tests. Furthermore, in experiments on $\mathrm{TI}$ a lack of naloxone effects has been described in rabbits (12), guinea pigs (13) and chickens (14). However, studies conducted on rabbits by Carli et al. $(15,16)$ have demonstrated the occurrence of analgesia during TI and have suggested that the pain response is blocked by a mechanism similar to that of morphine.

The mechanisms by which the endogenous analgesic system is activated under natural conditions remain unknown. One natural condition that activates the descending analgesic system is fear, such as that caused by exposure to a predator. It has been suggested that the central nucleus of the amygdala and periaqueductal grey matter pathway is an important network in fearinduced analgesia (17). The maneuvers used in the laboratory to induce TI are an attempt to simulate the physical restraint that occurs during predation and is accompanied by intense fear. Thus, it may be proposed that during TI there is activation of endogenous analgesic mechanisms responsible for the reduction in the nociceptive responses studied. On this basis, exposure to threatening stimuli has been shown to elicit forebrainmediated analgesia through fear circuits in the amygdala which in turn activate a descending pain inhibitory system in the brainstem (18-20). Hypoalgesia may be operationally defined as a partial reduction of the response to nociceptive stimulation (16). According to this definition, there is no doubt that hypoalgesia occurs during TI since we observed not only a significant reduction of flinches and lickings after formalin, but also an increased latency of the response to the hot-plate test. Indeed, with respect to formalin, licking the injected paw is unanimously considered to be an index of pain and a decrease of this behavior reflects hypoalgesia.

\section{References}

1. Basbaum Al \& Fields HL (1984). Endogenous pain control systems: brain-stem spinal pathways and endorphin circuitry. Annual Review of Neuroscience, 7: 309-338.

2. Watkins LR \& Mayer DJ (1986). Multiple endogenous opiate and nonopiate analgesic systems: evidence of their existence and clinical implications. Annals of the New York Academy of Sciences, 467: 273-299.

3. Rhudy J L \& Meagher MW (2000). Fear and anxiety: divergent effects on human pain thresholds. Pain, 84: 65-75.

4. Fanselow MS (1984). Shock-induced analgesia on the formalin test: effects of shock severity, naloxone, hypophysectomy, and associative variable. Behavioral Neuroscience, 98: 79-95.

5. Ratner SC (1967). Comparative aspects of hypnosis. In: Gordon J E (Editor), Handbook of Clinical and Experimental Hypnosis. MacMillan, New York.
6. Blanchard DC \& Blanchard RJ (1988). Ethoexperimental approaches of the biology of emotion. Annual Review of Psychology, 39: 43-68.

7. Rodgers RJ \& Randall JI (1987). Defensive analgesia in the rats and mice. The Psychological Record, 37: 335-347.

8. Fanselow MS \& Baackes MP (1982). Conditioned fear-induced opiate analgesia on the formalin test: evidence for two aversive motivational systems. Learning and Motivation, 13: 200-221.

9. Amir S (1986). Catalepsy induced by body pinch: relation to stress induced analgesia. Annals of the New York Academy of Sciences, 467: 226-237.

10. Zimmermann M (1983). Ethical guidelines for investigations of experimental pain in conscious animals. Pain, 16: 109-110.

11. Fanselow MS \& Helmstetter FJ (1988). Conditional analgesia, defensive freezing, and benzodiazepines. Behavioral Neuro- science, 102: 233-243.

12. Galeano C, Morcos R, Cloutier R, Desmarais PA \& Beaudry P (1978). The immobility reflex: effect of naloxone. Life Sciences, 23: 61-64.

13. Mucha RF (1980). Effect of naloxone and morphine on guinea pig tonic immobility. Behavioral and Neural Biology, 28: 111115.

14. Peters AH \& Hughes RA (1978). Naloxone interactions with morphine and shock potentiated tonic immobility in chickens. Pharmacology, Biochemistry and Behavior, 9: 153-156.

15. Carli G (1975). Some evidence of analgesia during animal hypnosis. Experimental Brain Research, 23 (Abstract collection): 35.

16. Carli G, Farabollini F, Fontani $G$ \& Grazzi F (1984). Physiological characteristics of pressure immobility. Effect of morphine, naloxone and pain. Behavioural Brain Re- 
search, 12: 55-63.

17. LeDoux J E, Iwata J , Cicchetti P \& Reis DJ (1988). Different projections of the central amygdaloid nucleus mediate autonomic and behavioral correlates of conditioned fear. J ournal of Neuroscience, 8: 2517-2529.

18. Meagher MW, Grau J W \& King RA (1990).
Role of supraspinal systems in environmentally induced antinociception: effect of spinalization and the descerebration on brief shock-induced and long shock-induced antinociception. Behavioral Neuroscience, 104: 328-338.

19. Helmstetter FJ \& Bellgowan PS (1993). Lesions of the amygdala block conditional hypoalgesia on the tail-flick test. Brain Research, 612: 253-257.

20. Fanselow MS (1994). Neural organization of the defensive behavior system responsible for fear. Psychonomic Bulletin \& Review, 1: 429-438. 